\title{
Diabetic Retinopathy in Greece: Prevalence and Risk Factors Studied in the Medical Retina Clinic of a Greek Tertiary Hospital
}

Maria Syriga ( $\triangle$ maria.syriga@gmail.com )

Hippokration General Hospital of Athens https://orcid.org/0000-0003-3476-5880

\section{Zina loannou}

Hippokration General Hospital of Athens

\section{Christos Pitsas}

Asklepieio Voulas, Athens

loanna Dagalaki

Hippokration General Hospital of Athens

\section{Michael Karampelas}

Hippokration General Hospital of Athens

\section{Research Article}

Keywords: diabetes, prevalence, Greek population, diabetic macular edema

Posted Date: May 5th, 2021

DOI: https://doi.org/10.21203/rs.3.rs-458090/v1

License: (c) (1) This work is licensed under a Creative Commons Attribution 4.0 International License. Read Full License

Version of Record: A version of this preprint was published at International Ophthalmology on January 31st, 2022. See the published version at https://doi.org/10.1007/s10792-021-02162-9. 


\section{Abstract}

Purpose: To determine the prevalence of diabetic retinopathy (DR) and diabetic macular edema (DME) in a cohort of Greek diabetic patients and identify possible risk factors.

Methods: Population-based, non-interventional, cross-sectional study of 300 diabetic Greek patients attending the medical retina clinics of a tertiary hospital. Clinical and imaging data were recorded and statistical analysis was performed. Confidence intervals $(\mathrm{Cl})$ at $95 \%$ and statistically significant $\mathrm{p}$ values $\leq 0.05$ were set.

Results: A total of 300 diabetic patients were included. Of these patients, 21 (7\%) were diagnosed with diabetes mellitus (DM) type I and 279 (93\%) with DM type II. The average duration of diabetes was $15 \pm$ 9.4 years $(95 \% \mathrm{Cl}, 13.9-16.1)$ and the mean level of $\mathrm{HbA1c}$ was $7.2 \pm 1.3(95 \% \mathrm{Cl}, 7.1-7.4)$ overall. Prevalence of DR was 38.7\% (116 patients), only 15 patients (5\%) had proliferative DR and diabetic macular edema (DME) was detected in 19 patients (6.3\%). In DM type I patients, $52.4 \%$ had DR and $9.5 \%$ had DME, while in the DM type II group, 37.6\% had DR and $6.1 \%$ had DME. Binary logistic regression analysis identified duration of diabetes, increased $\mathrm{HbA} 1 \mathrm{c}$ and hypertriglyceridemia as potential risk factors.

Conclusions: This study is the first one to present the extent and severity of DR and DME in a Greek cohort of diabetic patients and also identify risk factors associated with these entities. Our findings highlight the significance of a properly organized national screening program for the early detection and management of the vision threatening complications of DR.

\section{Introduction}

Diabetes mellitus (DM) has arisen as a major life- and vision-threatening condition, tightly associated with modern lifestyle and continuously growing industrialization. Globally, the number of people affected is increasing and is expected to reach up to 640 million by the year 2040 [1]. The disease complications can be divided in two categories; the macrovascular effects, including stroke, coronary and peripheral artery disease, and the microvascular complications, affecting the vascular network in the retina, kidneys and peripheral neurons. Diabetic retinopathy (DR) is diagnosed in 1 in 3 diabetic patients and can potentially lead to severe vision impairment or loss. Despite the extensive preventive measures taken, it still remains one of the main causes of reversible vision loss in working-age adults, therefore being characterized as a global epidemic [2]. The classification of DR is an essential tool for the proper identification and management of vision-threatening cases. One of the earliest attempts for the staging of DR was the establishment of the Airlie Classification system, whose modifications were applied in the Early Treatment Retinopathy Study (ETDRS) [3]. Regardless its' significance and accuracy, the application of this staging scheme is restricted due to its complexity. In an attempt to simplify the staging process and achieve the adequate communication and understanding among medical retina practitioners, new 
models were developed over the years. The International Clinical Disease Severity Scale for DR was introduced and recently modified according to ETDRS rules and clinical findings [4, 5].

According to this staging scale, DR is categorized as non-proliferative diabetic retinopathy (NPDR), which can be mild, moderate or severe, proliferative diabetic retinopathy (PDR), which can be non-high-risk and high-risk, and additionally the presence or absence of diabetic macular edema (DME) is noted. Visionthreatening forms of DR are attributed to either diabetic maculopathy or PDR and are estimated to occur in nearly one third of the diabetic patients globally [6].

Ethnic variation was previously studied as an independent risk factor for the prevalence of DR in several populations. Accordingly, among Asian countries, India and China have recorded the highest rate of DR [7], whilst in Western populations the disease prevalence was significantly higher in Hispanics and ethnic blacks $[8,9]$. On the opposite direction, Mediterranean populations present a healthier outcome, as far as cardiovascular risk is concerned $[10,11]$. Numerous studies link Greek ethnicity to a cardioprotective effect and they set the base for further investigation of this effect in microvascular entities, including DR [12] . Ethnic variations in the prevalence of DR are mainly attributed to different socioeconomic status and accessibility to health care as well as lifestyle and dietary influence [13], with Mediterranean diet presenting a thoroughly-studied vasoprotective effect $[14,15]$. Genetic studies previously conducted have proposed a heritable predisposition with the discovery of genetic loci implicated in the increased risk of DR [16].

At present, there is a paucity of literature concerning the epidemiology of DR in the Greek population. To the best of our knowledge, this is the first study to report the prevalence and risk factors of DR in a cohort of patients examined in a tertiary Greek hospital.

\section{Materials And Methods}

This is a population-based, non-interventional, cross-sectional study. Patients were recruited from the medical retina clinics of the Ophthalmology department of Hippocration General Hospital of Athens during September 2019 to March 2020. The study was approved by our institution's ethics committee and all data were anonymized. Inclusion criteria included Greek origin and diagnosis of DM which was defined in accordance with the American Diabetes Association criteria. Diagnosis of DM type 2 included non-fasting plasma glucose $>200 \mathrm{mg} / \mathrm{dl}(11.1 \mathrm{mmol} / \mathrm{l})$, glycated hemoglobin A1c $(\mathrm{HbA} 1 \mathrm{c})>6.5 \%$, physician-diagnosed diabetes or the use of glucose-lowering drugs and for type 1 DM was defined as the diagnosis of diabetes based on the previous criteria when the patient was $<30$ years and was subjected to insulin therapy [17]. Sufficient glycemic control was defined as the detection of $\mathrm{HbA} 1 \mathrm{c} \leq 7 \%$, while $\mathrm{HbA} 1 \mathrm{c} \geq 7 \%$ was categorized as poor diabetic control. Exclusion criteria included presence of other retinal abnormalities, either hereditary or acquired and any corneal or lens pathology that interfered with fundoscopy or optical coherence tomography (OCT). A consent form was signed prior participation in the study. The following clinical data were collected: age, sex, duration and type of diabetes, HbA1c, current medication, detailed medical and ophthalmic history. The definition of hypertension was based on the 
presence of systolic blood pressure (SBP) $>140 \mathrm{mmHg}$ and diastolic blood pressure (DBP) $>90 \mathrm{mmHg}$ or on the use of antihypertensive treatment. Lipid metabolism disorders (hypercholesterolemia and hypertriglyceridemia) were taken to be present when the patient was under lipid-lowering medication.

Best corrected visual acuity (BCVA) was measured according to Snellen vision chart and intraocular pressure (IOP) was assessed with Goldmann applanation tonometry taking into account central corneal thickness (CCT). Dilated retinal examination was performed by two medical retina specialists that were masked to all clinical information. DR grading was based according to the newest modification of the International Clinical Disease Severity Scale for DR [4, 5]. The presence of DME was assessed with OCT and PDR was diagnosed clinically and/or through fluorescein angiography (FA).

All data were collected and entered onto an Excel Microsoft database. For the analysis, only the eye with the worst outcome was included from each patient. Statistical analysis was performed using Statistical Package for the Social Sciences, version 2019 (SPSS Inc, Chicago, IL). Categorical data was described as absolute numbers and percentages while numerical variables as mean and \pm standard deviation. Normality was tested with Q-Q plots. Data were significantly skewed and therefore non-parametric tests were used. Differences in the proportions of categorical and numerical data were evaluated by Chi- and Mann-Whitney $\mathrm{U}$ test, respectively. Binary logistic regression analysis was assessed to determine factors associated with the presence and stages of DR. Confidence intervals (Cl) at $95 \%$ and statistically significant $p$ values $\leq 0.05$ were set.

\section{Results}

\section{Total cohort analysis}

A total of 300 patients were included. The average age was $69.6 \pm 11.8$ years ( $95 \% \mathrm{Cl}, 68.2-70.9 \%)$ ranging from 17 to 90 years old, while 153 were males (51\%) and 147 were females (49\%). Additionally, 21 patients (7\%) were diagnosed with DM type I and 279 (93\%) with DM type II. The average duration of diabetes was $15 \pm 9.4$ years $(95 \% \mathrm{Cl}, 13.9-16.1 \%)$ and the mean level of $\mathrm{HbA} 1 \mathrm{C}$ was $7.2 \pm 1.3(95 \% \mathrm{Cl}, 7.1$ 7.4).

184 patients $(61.3 \%)$ had no signs of diabetic retinopathy, 60 patients $(20 \%)$ had mild NPDR, 27 patients (9\%) had moderate NPDR, $14(4.7 \%)$ had severe NPDR while only 15 (5\%) patients had PDR. Good glycemic control was recorded in 157 patients (52.3\%). CMO was detected in 19 patients (6.3\%), while 16 patients $(5.3 \%)$ were previously subjected to PRP and $21(7 \%)$ to intravitreal anti-VEGF treatment (Table 1).

Patients diagnosed with any level of DR had statistically significant longer history of diabetes $(p=0.000)$, poor glycemic control $(p=0.009)$ and hypertriglyceridemia $(p=0.000)$ compared to those with no DR. (Table 2). Binary logistic regression analysis confirmed that duration of diabetes and elevated levels of $\mathrm{HbA1c}$ were strongly associated with the presence of $\mathrm{DR}(\mathrm{p}=0.000$ and $p=0.033$, respectively), while 
among the rest of the co-morbidities, only hypertriglyceridemia could be identified as a risk factor for DR $(p=0.001)$ (Table 2).

\section{Subgroup analysis}

For patients diagnosed with DM type I, the mean duration of diabetes was $23.9 \pm 10.4(95 \% \mathrm{Cl}, 19.2-28.7)$ while for DM type II patients was $14.3 \pm 9(95 \% \mathrm{Cl}, 13.3-15.4)$. Also, the mean level of HbA1c was $7.1 \pm 0.9$ $(95 \% \mathrm{Cl}, 6.7-7.5 \%)$ in patients with DM type I and 7.2 $\pm 1.3(95 \% \mathrm{Cl}, 7-7.4 \%)$ for DM type II; 14 patients with DM type I (66.7\%) and 144 (51.6\%) with DM type II had good glycemic control (Table 3).

The prevalence of DR in patients with DM type I was $52.4 \%$ (11 patients); 10 patients (47.6\%) had no signs of DR, 7 patients (33.3\%) had mild NPDR, 1 patient (4.8\%) had moderate NPDR and 3 patients (14.3\%) were diagnosed with PDR. From the group of DM type II, 174 patients (62.4\%) had no DR, 53 (19\%) had mild NPDR, 26 (9.3\%) had moderate NPDR, 14 (5\%) had severe NPDR and 12 (4.3\%) had PDR. CMO was detected in 2 patients (9.5\%) with DM type I and in 17 patients (6.1\%) with DM type II.

Statistical analysis for the comparison of clinical data between the two subtypes was not performed due to the significant difference in group sizes (Table 3).

In the group of DM type I patients, there was no statistically significant difference between patients diagnosed with no signs of DR and those with $D R$, as far as the gender $(p=0.835)$, duration of diabetes $(p=0.369)$, glycemic control $(p=0.103)$ and co-morbidities (hypertension $p=0.801$, hypercholesterolemia $p=0.525$ and hypertriglyceridemia $p=0.329$ ) were concerned (Table 4). Statistical analysis revealed that DM type I patients with signs of DR were older than those with no DR $(p=0.031)$, although this finding was not confirmed in binary logistic regression analysis (Table 4).

In the subgroup of DM type II, patients diagnosed with DR had longer history of diabetes $(p=0.002)$ and were under per os medication for the control of hypertriglyceridemia $(p=0.000)$, as confirmed by both Mann-Whitney $U$ test (Table 5). Additionally, age $(p=0.001)$, longer duration of diabetes $(p=0.000)$, elevated levels of HbA1c $(p=0.035)$ and hypertriglyceridemia $(p=0.002)$ were identified as risk factors for the development of DR in patients with DM type II through binary logistic regression analysis (Table 5).

\section{Discussion}

Prevalence of DR presents large variations amongst different ethnic groups worldwide [6, 18]. A vast number of studies estimating the extent and associated risk factors created a strong basis for the design of screening programs aiming towards the prevention of vision-threatening conditions arising from $D R$ [19]. The role of ethnic or population differences as a significant co-factor for the variability of DR globally was previously investigated [20-22]. These epidemiologic data could be attributed to differences in the socioeconomic status, lifestyle preferences and healthcare accessibility and also to the suspected role of the genetic background. Over the last decade, a large number of genetic studies has revealed genetic loci strongly related with the development and/or progression of DR, thus setting the stage for an ever-growing role in terms of genetic susceptibility research [23-25]. Greek ethnicity has drawn a 
significant amount of interest after the presentation of its cardioprotective effect in the Seven Countries study [26] and a number of publications followed pointing the favorable combination of Mediterranean lifestyle and genetic background in cardiovascular diseases [11,27, 28]. In the context of investigating the role of Greek ethnicity in microvascular entities, Brazionis et al., 2010 presented a lower prevalence of DR in Greek-born Australian citizens (23\%) compared to the Australian-born sub-cohort (37\%) and also that Greek ethnicity presented $68 \%$ lower odds of DR, after the adjustment for demographic and clinical variables [12]. However, to date there are no published studies available concerning the prevalence of DR in the Greek population.

The current study is the first one to present the extent and severity of DR and DME in a Greek cohort and also identify associated risk factors. The prevalence of DR was estimated at $38.7 \%$, DME at $6.3 \%$ and PDR at $5 \%$ of the participants. As far as the severity is concerned, the majority of patients diagnosed with signs of DR presented with mild NPDR (20\%), $9 \%$ had moderate and $4.7 \%$ had severe NPDR and $5 \%$ presented with PDR. Additionally, the proportion of patients subjected to PRP and/or intravitreal administration of anti-VEGF was as low as $5.3 \%$ and $7 \%$, respectively (Table 1 ).

A recent meta-analysis by J. Q. Li et al., 2019 presented the overall prevalence of DR and DME in Europe, extrapolating data from 35 studies that involved 205,743 patients in total [29]. The prevalence of any DR was $25.7 \%$ in both DM type I and type II, while therapeutic interventions due to PDR or DME were required in $2.2 \%$ and $3.7 \%$ of the patients, respectively. The majority of studies involved northern and southern European registries, followed by western and finally eastern Europe that included only one publication available from Hungary. The reported prevalence of DR was significantly elevated in northern (29.6\%) and southern $(25.8 \%)$ registries, followed by eastern $(20.1 \%)$ and western $(18.3 \%)$ Europe. In the same study, meta-analysis and meta-regression analysis by country presented that higher rates of DR were recorded in Italy (34.8\%), UK (29.8\%) and Spain (26.5\%) followed by Germany $(21.0 \%)$ and France $(14.6 \%)$. According to our findings, the prevalence of DR and DME in Greek diabetic patients is similar to the ones recorded in Italy, where DR and DME were $34.8 \%$ and $4.6 \%$, respectively. This finding could be attributed to the fact that these two countries share similarities in terms of lifestyle, dietary preferences and healthcare accessibility. The percentages of DR and DME recorded from Italy and from our Greek cohort are strikingly higher compared to the results presented from the rest of the European countries included in the meta-analysis from J. Q. et al., 2019 [29]. The validity and accuracy in these studies are strongly associated with the sources available for data collection in each country. In the UK, the majority of patients are registered in a national screening program while in Spain community eye clinics are responsible for the follow-up visits of all diabetic patients thus providing a large amount of data. In the rest of the European countries, including Greece, there are no official screening programs for DR and the information required is recorded mostly from patients that were either referred from another healthcare professional or patients seeking medical advice due to symptoms associated with DR. Therefore, the interpretation of these data as population-based should be considered with caution.

Previous studies in different populations around the globe have revealed a number of potential associations between DR and variables that concern demographic, socioeconomic and clinical aspects 
of each ethnic group [30-33]. Binary logistic regression analysis in this Greek cohort identified longer duration of diabetes $(p=0.000)$, poor glycemic control $(p=0.033)$ and lipid metabolism disorders $(p=0.001)$ as significant risk factors for the development of DR (Table 2). Also, distinct binary logistic regression analysis for DM type II patients revealed that duration of diabetes $(p=0.000)$, elevated levels of HbA1c $(p=0.035)$ and hypertriglyceridemia $(p=0.002)$ along with age $(p=0.001)$ are potential risk factors for the development of any stage of DR in these patients (Table 5). In the group of patients with DM type I, there was a statistically significant difference in the prevalence of $D R$ in older patients $(p=0.031)$, although this was not confirmed in binary logistic regression analysis $(p=0.746)$ (Table 4$)$. No further statistically significant differences were identified in this group, possibly due to the restricted number of patients included $(n=21)$. Hypertension and hypercholesterolemia were previously identified as the most common modifiable risk factors for DR [34-36]. However, in the current analysis these variables did not present a statistically significant association with the development of DR in the total cohort (Table 2) as well as in the subgroup analyses conducted for DM type I (Table 4) and DM type II patients (Table 5).

There are several limitations in our study. Grading of DR was assessed only through detailed clinical fundus examination due to limitations concerning the availability of imaging equipment. Also, the number of patients with DM type I was low, thus restricting the statistical analysis for the investigation of potential risk factors in this group. Finally, patients included in this cohort were referred to the medical retina clinic by other healthcare professionals or were self-referred due to the lack of a national screening program. Therefore, any extrapolation of our results to the Greek population should be done with great caution.

In conclusion, this is the first attempt to assess the prevalence of DR and DME and study associated risk factors in a cohort of Greek diabetic patients. Our findings are in consistency with previous results from studies of various ethnic populations presenting risk factors for the development of DR globally $[6,20,33$, 37-39]. Our study demonstrated that duration of DM is a significant factor that should be taken under consideration in the design of a national screening program for DR. Additionally, we found that both $\mathrm{HbA1c}$ and hypertriglyceridemia were significantly associated with DR and being modifiable risk factors, they could serve as important educational points for both healthcare professionals and patients. Taking under consideration the continuously increasing prevalence of DM and the significant financial burden in global healthcare, the current study aims to enrich the current statistics on DR and DME in Europe and create a base for further studies in the Greek population.

\section{Declarations}

\section{Acknowledgements}

The authors have no acknowledgements to share regarding this study.

\section{Funding}

The authors received no financial support for the research, authorship and/or publication of this article. 


\section{Disclosure of Interest}

None of the authors have any proprietary interests or conflicts of interest related to this submission.

\section{Availability of Data \& Material}

The datasets analyzed in the current study are available from the corresponding author on reasonable request.

\section{Code Availability}

Not applicable.

\section{Ethics Approval}

The study was approved by our institution's ethics committee.

\section{Consent to Participate}

A written consent form was obtained from each patient prior participation in the study.

\section{Consent for Publication}

A written consent form for publication was obtained from each patient prior participation in the study.

\section{References}

1. Ogurtsova K, da Rocha Fernandes JD, Huang Y, et al (2017) IDF Diabetes Atlas: Global estimates for the prevalence of diabetes for 2015 and 2040. Diabetes Res Clin Pract 128:40-50. https://doi.org/10.1016/j.diabres.2017.03.024

2. Saeedi P, Petersohn I, Salpea P, et al (2019) Global and regional diabetes prevalence estimates for 2019 and projections for 2030 and 2045: Results from the International Diabetes Federation Diabetes Atlas, 9th edition. Diabetes Res Clin Pract 157:107843. https://doi.org/10.1016/j.diabres.2019.107843

3. (1991) Early Treatment Diabetic Retinopathy Study design and baseline patient characteristics. ETDRS report number 7. Ophthalmology 98:741-756. https://doi.org/10.1016/s01616420(13)38009-9

4. Wu L, Fernandez-Loaiza P, Sauma J, et al (2013) Classification of diabetic retinopathy and diabetic macular edema. World J Diabetes 4:290-294. https://doi.org/10.4239/wjd.v4.i6.290

5. Wilkinson CP, Ferris FL, Klein RE, et al (2003) Proposed international clinical diabetic retinopathy and diabetic macular edema disease severity scales. Ophthalmology 110:1677-1682. https://doi.org/10.1016/S0161-6420(03)00475-5 
6. Yau JWY, Rogers SL, Kawasaki R, et al (2012) Global prevalence and major risk factors of diabetic retinopathy. Diabetes Care 35:556-564. https://doi.org/10.2337/dc11-1909

7. Sabanayagam C, Yip W, Ting DSW, et al (2016) Ten Emerging Trends in the Epidemiology of Diabetic Retinopathy. Ophthalmic Epidemiol 23:209-222. https://doi.org/10.1080/09286586.2016.1193618

8. Kempen JH, O'Colmain BJ, Leske MC, et al (2004) The prevalence of diabetic retinopathy among adults in the United States. Arch Ophthalmol 122:552-563.

https://doi.org/10.1001/archopht.122.4.552

9. Varma R, Bressler NM, Doan QV, et al (2014) Prevalence of and risk factors for diabetic macular edema in the United States. JAMA Ophthalmol 132:1334-1340.

https://doi.org/10.1001/jamaophthalmol.2014.2854

10. Knoops KTB, de Groot LCPGM, Kromhout D, et al (2004) Mediterranean diet, lifestyle factors, and 10year mortality in elderly European men and women: the HALE project. JAMA 292:1433-1439. https://doi.org/10.1001/jama.292.12.1433

11. Trichopoulou A, Costacou T, Bamia C, Trichopoulos D (2003) Adherence to a Mediterranean diet and survival in a Greek population. N Engl J Med 348:2599-2608. https://doi.org/10.1056/NEJMoa025039

12. Brazionis L, Rowley K, Itsiopoulos C, O'Dea K (2010) Is risk of diabetic retinopathy lower in Australia's Greek-born migrants? Diabet Med 27:660-665. https://doi.org/10.1111/j.1464-5491.2010.03005.x

13. Estruch R (2010) Anti-inflammatory effects of the Mediterranean diet: the experience of the PREDIMED study. Proc Nutr Soc 69:333-340. https://doi.org/10.1017/S0029665110001539

14. Grosso G, Mistretta A, Frigiola A, et al (2014) Mediterranean diet and cardiovascular risk factors: a systematic review. Crit Rev Food Sci Nutr 54:593-610.

https://doi.org/10.1080/10408398.2011.596955

15. Esposito K, Maiorino MI, Bellastella G, et al (2015) A journey into a Mediterranean diet and type 2 diabetes: a systematic review with meta-analyses. BMJ Open $5: e 008222$. https://doi.org/10.1136/bmjopen-2015-008222

16. Chong YH, Fan Q, Tham YC, et al (2017) Type 2 Diabetes Genetic Variants and Risk of Diabetic Retinopathy. Ophthalmology 124:336-342. https://doi.org/10.1016/j.ophtha.2016.11.016

17. American Diabetes Association (2010) Standards of medical care in diabetes-2010. Diabetes Care 33 Suppl 1:S11-61. https://doi.org/10.2337/dc10-S011

18. Flaxman SR, Bourne RRA, Resnikoff S, et al (2017) Global causes of blindness and distance vision impairment 1990-2020: a systematic review and meta-analysis. Lancet Glob Health 5:e1221-e1234. https://doi.org/10.1016/S2214-109X(17)30393-5

19. Ting DSW, Cheung GCM, Wong TY (2016) Diabetic retinopathy: global prevalence, major risk factors, screening practices and public health challenges: a review. Clin Exp Ophthalmol 44:260-277. https://doi.org/10.1111/ceo.12696

20. Wong TY, Klein R, Islam FMA, et al (2006) Diabetic retinopathy in a multi-ethnic cohort in the United States. Am J Ophthalmol 141:446-455. https://doi.org/10.1016/j.ajo.2005.08.063 
21. Chua J, Lim CXY, Wong TY, Sabanayagam C (2018) Diabetic Retinopathy in the Asia-Pacific. Asia Pac J Ophthalmol (Phila) 7:3-16. https://doi.org/10.22608/AP0.2017511

22. Lee R, Wong TY, Sabanayagam C (2015) Epidemiology of diabetic retinopathy, diabetic macular edema and related vision loss. Eye Vis (Lond) 2:17. https://doi.org/10.1186/s40662-015-0026-2

23. Grassi MA, Tikhomirov A, Ramalingam S, et al (2011) Genome-wide meta-analysis for severe diabetic retinopathy. Hum Mol Genet 20:2472-2481. https://doi.org/10.1093/hmg/ddr121

24. Huang Y-C, Lin J-M, Lin H-J, et al (2011) Genome-wide association study of diabetic retinopathy in a Taiwanese population. Ophthalmology 118:642-648. https://doi.org/10.1016/j.ophtha.2010.07.020

25. Dorajoo R, Liu J, Boehm BO (2015) Genetics of Type 2 Diabetes and Clinical Utility. Genes (Basel) 6:372-384. https://doi.org/10.3390/genes6020372

26. Simopoulos AP (2001) The Mediterranean diets: What is so special about the diet of Greece? The scientific evidence. J Nutr 131:3065S-73S. https://doi.org/10.1093/jn/131.11.3065S

27. Trichopoulou A, Critselis E (2004) Mediterranean diet and longevity. Eur J Cancer Prev 13:453-456. https://doi.org/10.1097/00008469-200410000-00014

28. Hernáez Á, Castañer O, Elosua R, et al (2017) Mediterranean Diet Improves High-Density Lipoprotein Function in High-Cardiovascular-Risk Individuals: A Randomized Controlled Trial. Circulation 135:633-643. https://doi.org/10.1161/CIRCULATIONAHA.116.023712

29. Li JQ, Welchowski T, Schmid M, et al (2020) Prevalence, incidence and future projection of diabetic eye disease in Europe: a systematic review and meta-analysis. Eur J Epidemiol 35:11-23. https://doi.org/10.1007/s10654-019-00560-z

30. Guo VY, Cao B, Wu X, et al (2016) Prospective Association between Diabetic Retinopathy and Cardiovascular Disease-A Systematic Review and Meta-analysis of Cohort Studies. J Stroke Cerebrovasc Dis 25:1688-1695. https://doi.org/10.1016/j.jstrokecerebrovasdis.2016.03.009

31. Penman A, Hancock H, Papavasileiou E, et al (2016) Risk Factors for Proliferative Diabetic Retinopathy in African Americans with Type 2 Diabetes. Ophthalmic Epidemiol 23:88-93. https://doi.org/10.3109/09286586.2015.1119287

32. Zheng Y, Lamoureux EL, Lavanya R, et al (2012) Prevalence and risk factors of diabetic retinopathy in migrant Indians in an urbanized society in Asia: the Singapore Indian eye study. Ophthalmology 119:2119-2124. https://doi.org/10.1016/j.ophtha.2012.04.027

33. Zhang X, Saaddine JB, Chou C-F, et al (2010) Prevalence of diabetic retinopathy in the United States, 2005-2008. JAMA 304:649-656. https://doi.org/10.1001/jama.2010.1111

34. Wat N, Wong RL, Wong IY (2016) Associations between diabetic retinopathy and systemic risk factors. Hong Kong Med J 22:589-599. https://doi.org/10.12809/hkmj164869

35. Tang J, Li T, Li P, et al (2018) Early Assessment of the Risk Factors for Diabetic Retinopathy Can Reduce the Risk of Peripheral Arterial and Cardiovascular Diseases in Type 2 Diabetes. Ophthalmic Res 59:221-227. https://doi.org/10.1159/000479931 
36. Murakami T, Kato S, Shigeeda T, et al (2020) Intensive treat-to-target statin therapy and severity of diabetic retinopathy complicated by hypercholesterolaemia. Eye (Lond). https://doi.org/10.1038/s41433-020-01202-5

37. Sivaprasad S, Gupta B, Gulliford MC, et al (2012) Ethnic variations in the prevalence of diabetic retinopathy in people with diabetes attending screening in the United Kingdom (DRIVE UK). PLoS One 7:e32182. https://doi.org/10.1371/journal.pone.0032182

38. Yan Z-P, Ma J-X (2016) Risk factors for diabetic retinopathy in northern Chinese patients with type 2 diabetes mellitus. Int J Ophthalmol 9:1194-1199. https://doi.org/10.18240/ijo.2016.08.17

39. Wong TY, Cheung N, Tay WT, et al (2008) Prevalence and risk factors for diabetic retinopathy: the Singapore Malay Eye Study. Ophthalmology 115:1869-1875.

https://doi.org/10.1016/j.ophtha.2008.05.014

\section{Tables}

Due to technical limitations, table 1-5 is only available as a download in the Supplemental Files section.

\section{Supplementary Files}

This is a list of supplementary files associated with this preprint. Click to download.

- Table1.xlsx

- Table2.xlsx

- Table3.xlsx

- Table4.xlsx

- Table5.xlsx 